\title{
A STUDY OF PREGNANCY EMERGED THROMBOCYTOPENIA AND ITS MATERNAL AND FETAL OUTCOME.
}

\author{
Fasiha Aziz ${ }^{1}$ and Vinutha Sharma ${ }^{1}$ \\ ${ }^{1}$ Dr Shankarrao Chavan Government Medical College
}

June 2, 2020

\begin{abstract}
A low platelet count is often an incidental finding in pregnancy. It can be an indicator of a severe systemic disorder requiring emergent maternal and fetal care or can just be unique to pregnancy with no harm to mother or fetus. Physiological decrease in platelet count is seen in pregnancy due to hemodilution and hypercoagulating state, though the exact pathophysiology is still unclear. Methods: It is a prospective observational study done in a tertiary care centre. Results: In about 11,258 cases screened 46 patients had thrombocytopenia $(0.4 \%)$. The commonest etiology is found to be gestational thrombocytopenia $(\mathrm{n}=$ $21,45.6 \%)$ followed by preeclampsia/ eclampsia/ HELLP syndrome $(\mathrm{n}=19,41.3 \%)$. Only one patient had ITP and $7(15.3 \%)$ were associated with AFLP. Maximum of them $(\mathrm{n}=19,41.3 \%)$ underwent spontaneous vaginal delivery.4 patients $(8.6 \%)$ had postpartum haemorrhage, 6 (13.04\%) had ceserean section wound infection, 4 (8.6\%) had DIC and 4 (8.6\%) had multiorgan failure.13 patients $(28.3 \%)$ had platelet count between 40 to 60 thousand per cumm, 11 (23.9\%) had between 60 to 80 thousand per cumm, 10 (21.7\%) had between 80,000to 1 lakh and none had their platelet count less than 20,000 per cumm. Conclusion: Gestational thrombocytopenia is not a preventable condition. It is an incidental finding in pregnancy. With strict vigilance during intrapartum and postpartum period, even without any treatment proper for the same, the maternal and fetal outcome is found to be good. Key words: HELLP, DIC, multiorgan failure.
\end{abstract}

\section{Hosted file}

vinutha_manuscript.docx available at https://authorea.com/users/328810/articles/456120-astudy-of-pregnancy-emerged-thrombocytopenia-and-its-maternal-and-fetal-outcome

\section{Hosted file}

revised tables.docx available at https://authorea.com/users/328810/articles/456120-a-studyof-pregnancy-emerged-thrombocytopenia-and-its-maternal-and-fetal-outcome 